\title{
The epidemiology of hepatitis B virus infection in Korea
}

\author{
Sun Young Yim and Ji Hoon Kim
}

Division of Gastroenterology and Hepatology, Department of Internal Medicine, Korea University Medical Center, Seoul, Korea

Received: January 7, 2019

Accepted: January 31, 2019

\section{Correspondence to}

Ji Hoon Kim, M.D.

Division of Gastroenterology and Hepatology, Department of Internal Medicine, Korea

University Medical Center, 148

Gurodong-ro, Guro-gu, Seoul

08308, Korea

Tel: +82-2-2626-3011

Fax: +82-2-2626-1038

E-mail: kjhhepar@korea.ac.kr

https://orcid.org/0000-0003-3924-0434
The global burden of hepatitis B virus (HBV) infection is profound, and represents a public health threat as chronic infection can lead to liver cirrhosis, hepatocellular carcinoma, and death. The risk factors for chronic hepatitis B-related liver disease differ according to HBV endemicity, hepatitis B e-antigen seropositivity, and viral load. It is important to identify these risk factors and start antiviral treatment at an appropriate time according to current guidelines. The most crucial step in reducing HBV infection is prevention in infancy or early childhood, as infection at an early stage may lead to chronicity. South Korea was formerly an HBV-endemic area, but the epidemiology of HBV infection was changed by the introduction of vaccination in 1983 and nationwide immunization in 1995. The government and the private sector made efforts to reduce the prevalence of $\mathrm{HBV}$ infection, and Korea is on target to meet the World Health Organization goal of eliminating viral hepatitis by 2030. To eliminate hepatitis worldwide, the costs of antiviral treatment to prevent perinatal HBV transmission in pregnant women with high viremia should be covered by a national program, and strategies to reduce the prevalence of HBV infection in immigrant populations are needed.

Keywords: Hepatitis B, chronic; Vaccination; Epidemiology

\section{INTRODUCTION}

The World Health Organization (WHO) Global Strategy for Viral Hepatitis was approved during the World Health Assembly in May 2016. Hepatitis was elevated to a higher priority with a goal of eliminating viral hepatitis as a public health threat by 2030. The goal of the WHO is to achieve a $90 \%$ reduction in the incidence of chronic hepatitis B (CHB) and $\mathrm{C}$ infection and a 65\% reduction in the mortality rate of viral hepatitis by 2030 . Therefore, it is necessary to understand the current status of, and establish reliable strategies to eliminate, hepatitis B virus (HBV) infection in Korea.

South Korea is an intermediate endemic area for HBV infection; the estimated prevalence was approximately $3 \%$ in the 2016 Korea National Health and
Nutrition Examination Survey (KNHANES) [1]. Chronic HBV infection is a major cause of liver cirrhosis and hepatocellular carcinoma (HCC) [2]. However, dramatic progress has been made in the management of chronic HBV infection after the introduction of HBV vaccination, nationwide screening and advances in antiviral treatment [3]. Here we review the changing epidemiology and burden of HBV infection and strategies to control HBV infection in Korea.

\section{EPIDEMIOLOGY}

\section{Chronic hepatitis B prevalence}

The WHO estimated that in 2015, 257 million persons or $3.5 \%$ of the population were living with chronic HBV 
Table 1. Levels of hepatitis B virus endemicity

\begin{tabular}{lclc}
\hline Types of endemicity & HBsAg prevalence, \% & \multicolumn{1}{c}{ Mode of infection } & Geographic distribution \\
\hline High & $\geq 8$ & Perinatal transmission & Parts of sub-Saharan Africa \\
Intermediate & $2-7$ & Perinatal and horizontal transmission & $\begin{array}{c}\text { Eastern Europe; Central Asia; } \\
\text { Southeast Asia; China; Japan }\end{array}$ \\
Low & $<2$ & Horizontal transmission & United States; Western Europe \\
\hline
\end{tabular}

Adapted from World Health Organization [5].

HBsAg, hepatitis B surface antigen.

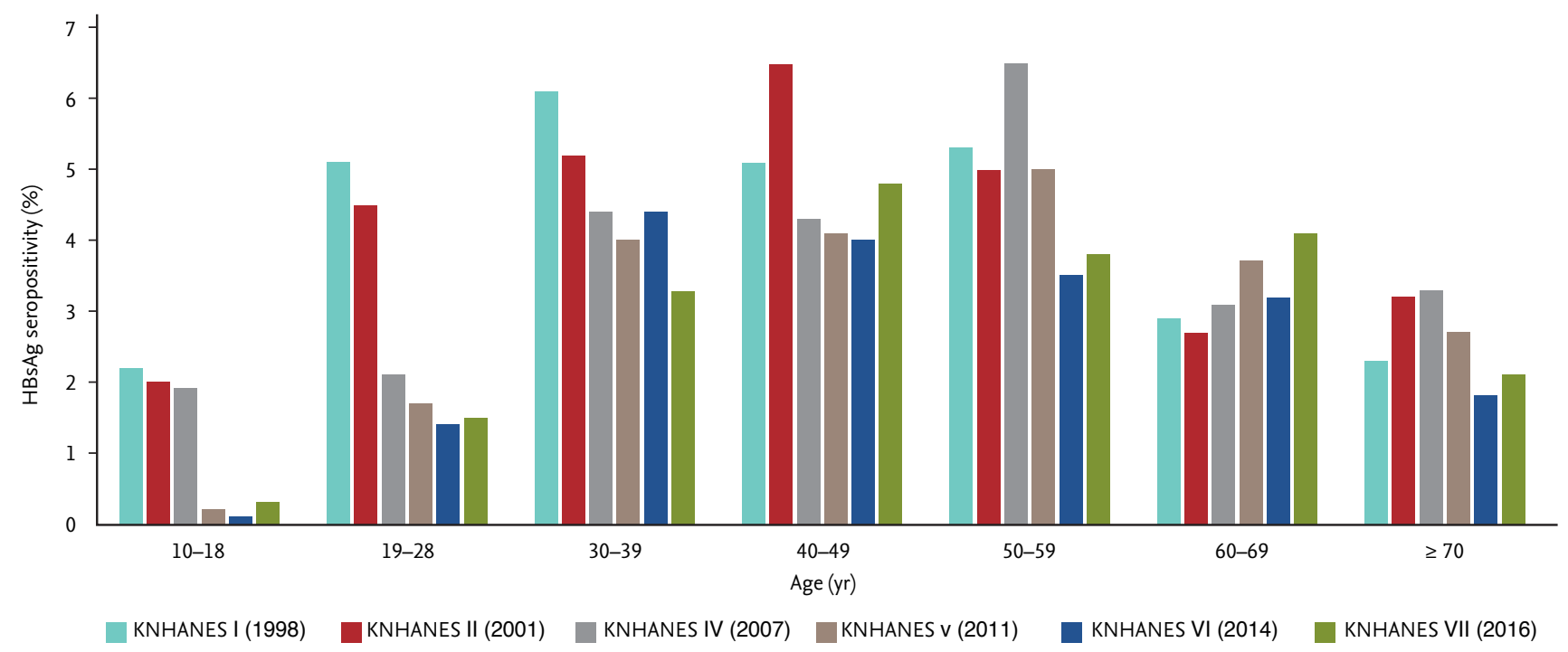

Figure 1. Changes in the prevalence of hepatitis B virus carriage according to age group. Adapted from Korea Centers for Disease Control \& Prevention [1]. HBsAg, hepatitis B surface antigen; KNHANES, Korea National Health and Nutrition Examination Survey.

infection. Among HBV-infected patients, approximately 27 million (10.5\%) were aware of their infection and an estimated 4.5 million (16.7\%) of them were on treatment. The prevalence of HBV infection differs geographically: $6 \%$ in Africa, $2 \%$ in Southeast Asia, and $1 \%$ in the Americas [4].

HBV endemicity differs according to the mode of infection (Table 1) [5]. Countries with a high prevalence have perinatal transmission as the major mode of infection; while low prevalence was due to horizontal transmission. Transmission by both modes is important in countries with an intermediate prevalence, such as South Korea, due to vaccination, perinatal care, and public health. The HBV disease burden in Korea results mainly from infections acquired through perinatal transmission. However, after implementation of a vaccination program in 1983, Korea was classified as an area of intermediate endemicity. The prevalence of hepatitis
B surface antigen (HBsAg) carriage was $8 \%$ to $10 \%$ in the $1980 \mathrm{os}, 4.6 \%$ in the $1990 \mathrm{Os}$, and has remained at $2.9 \%$ since 2010. HBV vaccination for all newborns was introduced in 1983 (coverage rate, $79.7 \%$ ), and the Expanded Program on Immunization (EPI) was introduced in 1995 (coverage rate, 98.9\%) [1,6]. The HBsAg-positivity rates of younger age groups markedly declined to $2.2 \%$ in 1998 , $1.9 \%$ in $2001,1.9 \%$ in 2007 , and $0.3 \%$ in 2016 . The prevalence of HBsAg carriage also decreased significantly among those in their 2os and 30 (Fig. 1). The prevalence of CHB in Korean children has met the WHO interim 2020 target, $1 \%$ in children aged 5 years, and is projected to decline to $0.1 \%$ by 2030 .

The overall HBsAg positivity rate was slightly higher in men than in women, but the difference gradually decreased from $1.1 \%$ in 1998 to $0.3 \%$ in 2016. In 2016, the rate was highest in men and women in their $40 \mathrm{OS}$ and $50 \mathrm{OS}(5.7 \%$ and $4.7 \%$, respectively) (Fig. 2) [1]. HBsAg 


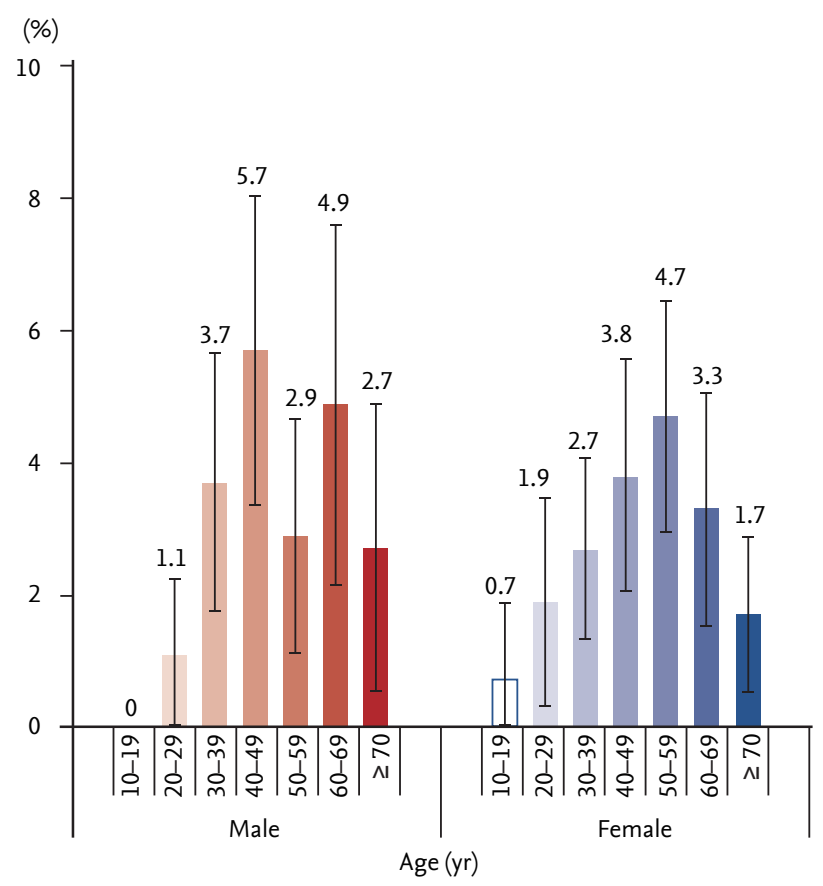

Figure 2. Prevalence of hepatitis B virus carriage according to age and gender. Adapted from Korea Centers for Disease Control \& Prevention [1].

seropositivity did not differ between low (2.6\%) and high income (2.4\%) groups or between urban (2.9\%) and $\operatorname{rural}(2.5 \%)$ residents $[1]$.

\section{Incidence of acute hepatitis B}

The trends of acute hepatitis B changed in response to implementation of the HBV vaccination program. The incidence of acute viral hepatitis A and B among overall acute hepatitis in the early 1990 s was $3.4 \%$ and $60.3 \%$, respectively, with $\mathrm{HBV}$ infection as the most common cause of acute hepatitis [7]. In 2008, the incidence of acute $\mathrm{HBV}$ infection decreased to $5 \%$, while that of acute hepatitis A virus infection increased to 70\% [8]. The most frequently infected age group was 10 to 29 years of age in the 1980s, and 30 to 39 years of age in the early 2000 s (Fig. 3) [9]. Approximately $5 \%$ of all acute HBV infections progress to chronic infection [10].

In patients who recover from acute hepatitis B, HBV replication may persist in some organs, most likely the liver or peripheral blood cells, for a long period despite the presence of serum antibodies to HBsAg (anti-HBs) and HBV-specific cytotoxic T-cells [11,12]. HBV DNA was detected in the liver tissues of 13 of 14 healthy liver

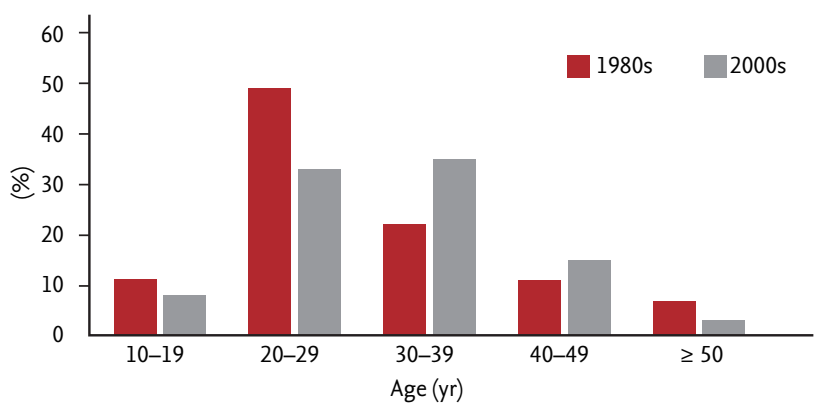

Figure 3. Age distribution of acute hepatitis B patients in the 1980 s and 2000 s. Adapted from Yim et al. [8] and Choi et al. [9].

transplant donors who were positive for hepatitis B core antibody (anti-HBc) and anti-HBs [13]. Persistent histological abnormalities, including fibrosis and mild inflammation, were present for 10 years in another study, despite complete serological recovery after acute infection [14].

HBsAg-negative but anti-HBc-positive patients are at risk of HBsAg reversion, particularly during rituximab-based chemotherapy. Therefore, HBsAg and anti-HBc should be monitored in patients who are candidates for rituximab-based chemotherapy or bone marrow transplantation [15-17]. Because HBV transmission may still occur in unvaccinated and uninfected adults and can lead to chronicity, "catch-up" HBV vaccination should be given to prevent acute HBV infection in individuals who were not vaccinated in early childhood.

\section{BURDEN OF CHRONIC HEPATITIS B VIRUS INFECTION}

\section{Disease course}

The frequency of complications varies geographically. In low-endemic areas, the incidence of liver-related complications in untreated, asymptomatic patients can be as low as $1.2 \%$ after 16 years [18]. By contrast, the 5-year cumulative incidence of cirrhosis in East Asian (Taiwan and Korea) patients with hepatitis B e-antigen (HBeAg)-positive and -negative hepatitis was 8\% to $17 \%$ and $13 \%$ to $38 \%$, respectively. The 5 -year cumulative incidence of liver decompensation among patients with cirrhosis was $15 \%$. The incidence of HCC differs according to liver disease status; the 5-year cumulative in- 
cidence was $1 \%$ in inactive carriage, $3 \%$ in $\mathrm{CHB}$ patients without cirrhosis, and $17 \%$ in those with cirrhosis [19]. The 5-year cumulative incidence of survival in patients with compensated and decompensated cirrhosis was $85 \%$ and $14 \%$ to $35 \%$, respectively [19-21]. The prevalence was similar in Korea before the era of antiviral agents, and the predominant cause of HCC was HBV infection (62\% to $75 \%$ of $\mathrm{HCC})[22]$.

After the introduction of oral antiviral therapy in 1999, the epidemiology of liver disease and liver cancer in Korea changed [23]. Real-world population-level data from the national death certificate database of Korea for liver disease and liver cancer showed that the annual number of patients receiving oral antivirals increased from 1,716 to 187,226 from 1999 to 2013 . Long-term treatment induced histological improvement, including reversal of cirrhosis and reducing the incidence of HCC $[24,25]$. The 5-year cumulative incidence of cirrhosis decreased from $23 \%$ before the era of antiviral therapy to $5.3 \%$ in the era of antiviral therapy, that of hepatic decompensation from $5 \%$ to $0.3 \%$, and the incidence of HCC from $3 \%$ to $0.8 \%$ [26].

There was a dissociation of mortality trends between liver disease and liver cancer despite use of antiviral agents. The crude death rate (CDR) for liver disease decreased from 21.2 to 7.5 per 100,000 persons $(64.6 \%$ decrease). This reduction is far greater than that reported in a study from Taiwan (8\%), also an HBV-endemic area [27]. In contrast, the CDR for liver cancer increased from $20.5 \%$ to $22.6 \%$ (10.2\% increase). The mean age at death from liver disease increased by 8.8 years, significantly greater than the 6.1-year increase for liver cancer and 6.3-year increase for the entire population during the same period. The marked reduction in liver disease mortality due to newborn vaccination and widespread use of antivirals for HBV may have increased the life expectancy and number of patients at risk of developing liver cancer, inadvertently leading to an increased burden of liver cancer in HBV-endemic areas [28,29]. Although the mortality rate of liver disease has decreased, patients with liver cancer have a high mortality rate. This suggests the need for early screening for HCC in patients with HBV infection.

\section{Risk factors that influence the disease course}

Both virologic and non-virologic factors influence dis- ease progression and survival in chronic HBV-infected patients. The factors associated with disease activity include $\mathrm{HBeAg}$ seropositivity, HBV DNA and HBsAg levels, and HBV genotype. HBV variants such as core promoter or pre-S deletion variants are associated with progressive liver disease and HCC [30,31]. Among these factors, the serum HBV DNA level is the cardinal predictor of disease progression in patients with a high viral load $(\geq 2,000 \mathrm{IU} / \mathrm{mL})$, and is a determinant of the risk of progression in those with an HBV DNA level < 2,000 IU/mL [32].

In HBeAg-negative patients with an HBV DNA level $<2,000 \mathrm{IU} / \mathrm{mL}$, the serum HBsAg level is predictive of liver disease progression. An HBsAg level > 1,000 IU/mL is associated with an increased risk of disease progression [33,34]. Among HBeAg-positive patients, a high viral load is generally not predictive of complications, but a moderately high HBV DNA level (> 20,000 IU/mL) and advanced age are closely associated with an increased risk of HCC compared to that of immune-active phase CHB patients treated with nucleos(t)ide analogues. This suggests the need for earlier antiviral treatment in certain immune-tolerant CHB patients [35].

Spontaneous HBsAg clearance occurs infrequently; the annual incidence is $0.5 \%$ to $2.3 \%$ [36-38]. The annual HBsAg seroclearance rate is lower in Korea (0.76\%) than in other countries. The difference may be due to HBV genotype; the majority of Korean patients are infected with genotype C HBV [39]. After HBsAg seroclearance, the annual rate of HCC development was $0.55 \%$ and the associated risk factors were liver cirrhosis, male gender, and age $\geq 45$ to 50 years at the time of HBsAg seroclearance $[40,41]$. Therefore, HCC surveillance is required in patients with these risk factors even after HBsAg seroclearance.

\section{Economic burden of HBV-related disease}

In 2005, the societal cost of HBV infection was 1.937 trillion KRW, including direct costs of 474,642 million KRW and indirect costs of 1.463 trillion KRW (Table 2) [42]. This is equivalent to $0.24 \%$ of the 2005 Korean gross domestic product (GDP), or 3.98\% of Korea's 2005 national health expenditure (NHE) and $2.01 \%$ of annual national health insurance expenditure. However, the economic burden is anticipated to decrease due to vaccination and prevention of perinatal transmission. 
Table 2. Societal costs of hepatitis B virus-related diseases in 2005 (million KRW, \%)

\begin{tabular}{lccc}
\hline Liver disease & Direct costs & Indirect costs & Total \\
\hline Chronic hepatitis B & 134,528 & 330,640 & $465,167(24)$ \\
Cirrhosis & 112,284 & 421,165 & $433,446(27.8)$ \\
Hepatocellular carcinoma & 173,084 & 690,856 & $863,940(44.6)$ \\
Liver transplantation & 54,746 & 19,888 & $74,635(3.9)$ \\
Total costs & 474,642 & $1,462,549$ & $1,937,191(100)$ \\
\hline
\end{tabular}

Values are presented as number (\%). Adapted from Yang et al. [42], with permission from Springer Nature.

KRW, Korea won.

\section{STRATEGIES TO CONTROL HEPATITIS B}

\section{Vaccination}

The risk of becoming an HBsAg carrier is 90\% for perinatal infection, $25 \%$ to $30 \%$ for infection acquired during the preschool years, and less than $10 \%$ for adults [43]. Korea was classified as an area of high endemicity before implementing universal vaccination; in the 1980 s, around $11 \%$ of neonates in Korea were infected with HBV via vertical transmission [6]. The domestically developed plasma-derived hepatitis $B$ vaccine was approved in Korea in 1983. The first dose of monovalent hepatitis B vaccine is given as soon as possible after birth, preferably within 24 hours, followed by at least two subsequent booster doses at 1 and 6 months. After the introduction of hepatitis B vaccination for all newborns, the coverage rate was $79 \%$; this was further increased to $94 \%$ (third dose) through the implementation of the EPI in 1995, higher than the global rate of $84 \%$ [4].

\section{Prevention of vertical transmission}

The Korea Advisory Committee on Immunization Practices (KACIP) implemented the Hepatitis B Perinatal Transmission Prevention Program (HBPTPP) in July 2002. This program aimed to screen all pregnant women for CHB infection, provide prophylactic treatment (hepatitis B immunoglobulin [HBIG]) to all infants born to HBsAg-positive mothers, and vaccinate all infants against hepatitis B. To ensure compliance among providers and patients in the private sector, the government provided full financial support. A voucher system was implemented to cover the cost of vaccination and to track progress. Voucher information is sent to the Korea CHB database.

Infants born to HBsAg-positive mothers receive
HBIG at birth in addition to vaccination. This has reduced the HBsAg prevalence among blood donors to ०\% to $0.4 \%$ (Fig. 4), and the third-dose coverage rate among infants is $94 \%$ (Table 3). In 2008, the WHO certified that Korea has achieved control of vertical transmission of HBV [44].

\section{Antiviral therapy in pregnant women with high viremia} The HBPTPP was reviewed in 2011 and among 69,999 children that were enrolled in this program with available follow-up serological test results, prophylaxis failure rate was $3.14 \%$. A high viral load in the mother is a major risk factor for post-birth HBV vaccine failure [45]. Immunoprophylaxis may fail in infants born to mothers with an HBV DNA level > 200,000 IU/mL, HBeAg seropositivity, and an HBsAg level < 10,000 IU/ $\mathrm{mL}[46,47]$. Recent study from China showed that prophylactic tenofovir in HBsAg-positive mothers with an HBV DNA level $>200,000 \mathrm{IU} / \mathrm{mL}$ during the third trimester decreased the rate of mother-to-child transmission [48]. Concerning the safety of tenofovir, no adverse events have been observed in mothers and infants [49]. Our recent meta-analysis also showed that tenofovir prevented vertical transmission and had no significant adverse events [50]. Global guidelines now recommend tenofovir to prevent vertical transmission in the third trimester of pregnancy [16], but health insurance does not cover the cost of antiviral therapy for pregnant women with only a high HBV DNA level. Thus, these data could provide evidence to a policy change for the coverage of antiviral costs in addition to vaccination program.

\section{Catch-up vaccination}

In the national immunization guidelines for adults, 


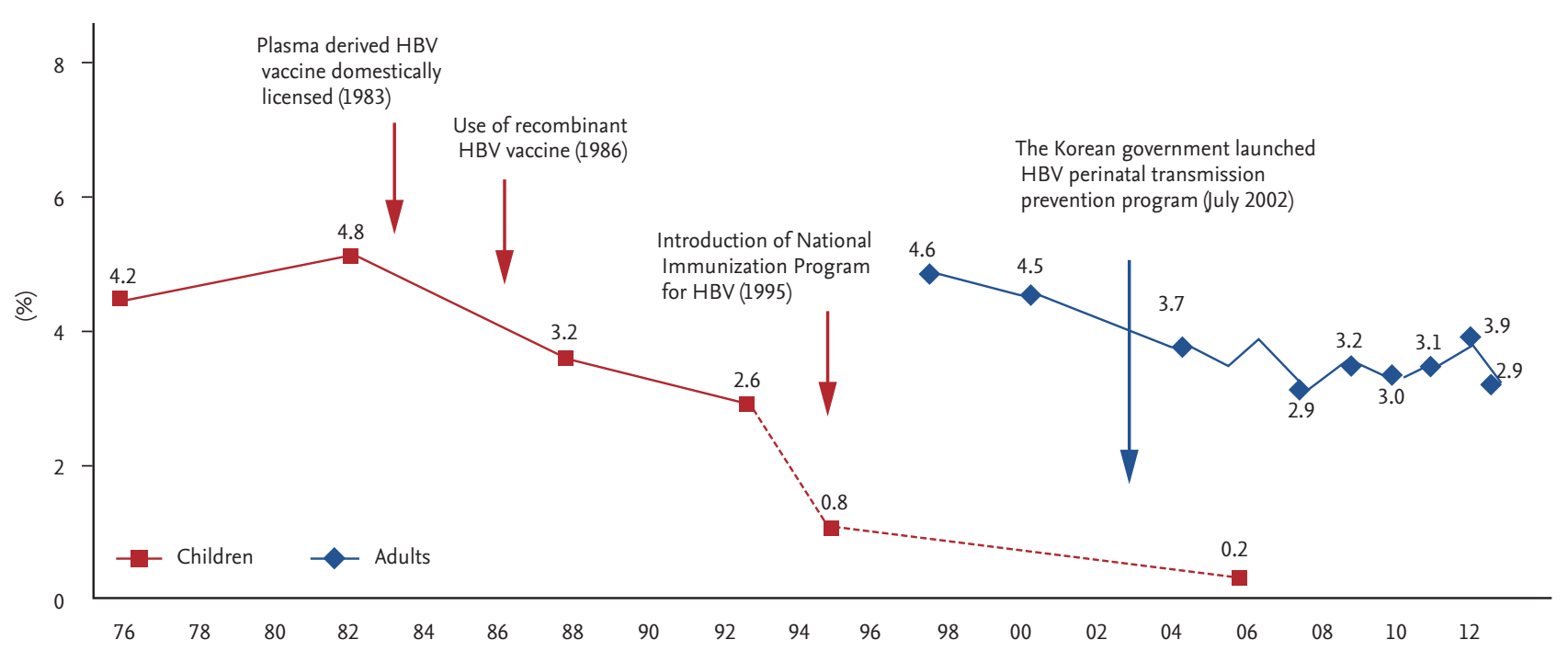

Figure 4. Changes in the prevalence of hepatitis B virus (HBV) carriers after introduction of the national HBV vaccination program. Adapted from Cho et al. [2].

Table 3. Registered infants born to hepatitis B surface antigen (HBsAg)-positive mothers in the Hepatitis B Perinatal Transmission Prevention Program, July 2002 to June 2012

\begin{tabular}{lccccccccccccc}
\hline & Total & $\begin{array}{c}2002 \\
(\mathrm{Jul}-)\end{array}$ & 2003 & 2004 & 2005 & 2006 & 2007 & 2008 & 2009 & 2010 & $\begin{array}{c}2011 \\
\text { (Jan-Jun) }\end{array}$ \\
\hline $\begin{array}{l}\text { No. of infants at risk of } \\
\text { perinatal hepatitis B } \\
\text { infection }\end{array}$ & 153,235 & 7,857 & 16,678 & 16,074 & 14,791 & 15,237 & 15,783 & 14,909 & 14,235 & 15,045 & 15,084 & 7,542 & \\
$\begin{array}{l}\text { No. of newly registered } \\
\text { infants }\end{array}$ & 147,737 & 5,394 & 14,586 & 15,410 & 14,411 & 15,002 & 16,483 & 15,266 & 14,547 & 14,760 & 14,976 & 6,902 \\
Registered, \% & 96.4 & 68.7 & 87.5 & 95.9 & 97.4 & 98.5 & 104.4 & 102.4 & 102.2 & 98.1 & 97.1 & 91.5 & \\
\hline
\end{tabular}

Estimated number of infants at risk of perinatal hepatitis B infection $=$ number of live births $\times 0.032$ (HBsAg seropositivity of pregnant women). Adapted from Korea Centers for Disease Control \& Prevention [1].

catch-up hepatitis B vaccinations are recommended for adults without a history of immunization or who had past HBV infection, particularly those with chronic liver diseases, hemodialysis, human immunodeficiency virus infection, or who are frequent recipients of blood products, as well as persons at elevated risk of exposure to HBV (residents and staff of facilities for people with developmental disabilities, prisoners, employees of correctional facilities, people with household contact to someone who is HBsAg-positive, injection drug users, or people with sexually transmitted infections) [45].

\section{Management of HBV infection in immigrant popu- lations}

According to monthly statistics published by the Min- istry of Justice and Korea Immigration Service, in 2015 there were 1,774,603 foreigners in Korea, more than half of whom were from HBV-endemic areas. Ongoing immigration from countries with high endemicity such as China $(918,951,51.8 \%)$, Vietnam $(129,423,7.3 \%)$, the Philippines (51,836, 2.9\%), and Indonesia (42,520, 2.4\%), as well as the increasing number of North Korean defectors (HBV prevalence, 10.9\%), represents a public health threat to South Korea and warrants government intervention.

\section{CONCLUSIONS}

Hepatitis B vaccination has substantially reduced the 
prevalence of HBV carriage, and the development of highly effective antivirals has decreased the incidence of liver disease. Advances in prevention and management within three decades have changed the epidemiology of CHB and give cause for optimism that hepatitis B will be eliminated by 2030 followed by reduction in societal burden. However, further effort is required in a new perspective such as prevention of $\mathrm{HBV}$ infection in immigration population and coverage of antiviral costs by a national program in pregnant women with high viremia.

\section{Conflict of interest}

No potential conflict of interest relevant to this article was reported.

\section{REFERENCES}

1. Korea Centers for Disease Control \& Prevention. Korea National Health and Nutrition Examination Survey (KNHANES) 2016 [Internet]. Cheongju (KR): KCDC, 2016 [cited 2019 Feb 11]. Available from: http://knhanes.cdc.go.kr.

2. Cho EJ, Kim SE, Suk KT, et al. Current status and strategies for hepatitis B control in Korea. Clin Mol Hepatol 2017;23:205-211.

3. Kim BH, Park JW. Epidemiology of liver cancer in South Korea. Clin Mol Hepatol 2018;24:1-9.

4. World Health Organization. Global Hepatitis Report 2017. Geneva (CH): WHO, 2017.

5. World Health Organization. Hepatitis B vaccines: WHO position paper (July 2017) [Internet]. Geneva (CH): WHO, c2019 [cited 2019 Feb 11]. Available from: https://www.who. int/immunization/policy/position_papers/hepatitis_b/en/.

6. Park NH, Chung YH, Lee HS. Impacts of vaccination on hepatitis B viral infections in Korea over a 25-year period. Intervirology 2010;53:20-28.

7. Lee HS, Byun JH, Kim CY. Etiology and outcome of acute viral hepatitis in Korean adults. J Korean Med Sci 1990;5:149-154.

8. Jeong SH. Current status and vaccine indication for hepatitis A virus infection in Korea. Korean J Gastroenterol 2008;51:331-337.

9. Yim HJ, Chang YJ, Byun KS, et al. The changing patterns of acute hepatitis B infection in Korea in the early 2000's. Korean J Med 2005;69:601-607.
10. Choi HJ, Ko SY, Choe WH, et al. Clinical features of acute viral hepatitis B in Korea: a multi-center study. Korean J Hepatol 2011;17:307-12.

11. Yotsuyanagi $\mathrm{H}$, Yasuda $\mathrm{K}$, Iino S, et al. Persistent viremia after recovery from self-limited acute hepatitis B. Hepatology 1998;27:1377-1382.

12. Rehermann B, Ferrari C, Pasquinelli C, Chisari FV. The hepatitis B virus persists for decades after patients' recovery from acute viral hepatitis despite active maintenance of a cytotoxic T-lymphocyte response. Nat Med 1996;2:1104-1108.

13. Marusawa $H$, Uemoto S, Hijikata M, et al. Latent hepatitis $\mathrm{B}$ virus infection in healthy individuals with antibodies to hepatitis B core antigen. Hepatology 2000;31:488-495.

14. Yuki N, Nagaoka T, Yamashiro M, et al. Long-term histologic and virologic outcomes of acute self-limited hepatitis B. Hepatology 2003;37:1172-1179.

15. Pattullo V. Prevention of hepatitis B reactivation in the setting of immunosuppression. Clin Mol Hepatol 2016;22:219-237.

16. European Association for the Study of the Liver. Electronic address: easloffice@easloffice.eu; European Association for the Study of the Liver. EASL 2017 clinical practice guidelines on the management of hepatitis $\mathrm{B}$ virus infection. J Hepatol 2017;67:370-398.

17. Korean Association for the Study of the Liver. KASL clinical practice guidelines: management of chronic hepatitis B. Clin Mol Hepatol 2016;22:18-75.

18. Villeneuve JP, Desrochers M, Infante-Rivard C, et al. A long-term follow-up study of asymptomatic hepatitis B surface antigen-positive carriers in Montreal. Gastroenterology 1994;106:1000-1005.

19. Fattovich G, Bortolotti F, Donato F. Natural history of chronic hepatitis B: special emphasis on disease progression and prognostic factors. J Hepatol 2008;48:335-352.

20. Fattovich G, Giustina G, Schalm SW, et al. Occurrence of hepatocellular carcinoma and decompensation in western European patients with cirrhosis type B. The EUROHEP Study Group on Hepatitis B Virus and Cirrhosis. Hepatology 1995;21:77-82.

21. Liaw YF, Lin DY, Chen TJ, Chu CM. Natural course after the development of cirrhosis in patients with chronic type B hepatitis: a prospective study. Liver 1989;9:235-241.

22. Yoon SK, Chun HG. Status of hepatocellular carcinoma in South Korea. Chin Clin Oncol 2013;2:39.

23. Jung KW, Won YJ, Kong HJ, Lee ES; Community of Popu- 
lation-Based Regional Cancer Registries. Cancer statistics in Korea: incidence, mortality, survival, and prevalence in 2015. Cancer Res Treat 2018;50:303-316.

24. Wong GL, Chan HL, Mak CW, et al. Entecavir treatment reduces hepatic events and deaths in chronic hepatitis $\mathrm{B}$ patients with liver cirrhosis. Hepatology 2013;58:1537-1547.

25. Wu CY, Lin JT, Ho HJ, et al. Association of nucleos(t)ide analogue therapy with reduced risk of hepatocellular carcinoma in patients with chronic hepatitis B: a nationwide cohort study. Gastroenterology 2014;147:143-151.

26. Kim CY, Kim JW, Lee HS, Yoon YB, Song IS. Natural history and survival rate of chronic liver diseases in Korea: 20 years prospective analysis. Korean J Med 1994;46:168-180.

27. Chiang CJ, Yang YW, Chen JD, et al. Significant reduction in end-stage liver diseases burden through the national viral hepatitis therapy program in Taiwan. Hepatology 2015;61:1154-1162.

28. Choi J, Han S, Kim N, Lim YS. Increasing burden of liver cancer despite extensive use of antiviral agents in a hepatitis B virus-endemic population. Hepatology 2017;66:14541463.

29. Yim SY, Seo YS, Jung CH, et al. The management and prognosis of patients with hepatocellular carcinoma: what has changed in 20 years? Liver Int 2016;36:445-453.

30. Yim SY, Um SH, Young Jung J, et al. Clinical significance of hepatitis B virus precore and core promoter variants in Korean patients with chronic hepatitis B. J Clin Gastroenterol 2015;49:61-68.

31. Lin CL, Kao JH. New perspectives of biomarkers for the management of chronic hepatitis B. Clin Mol Hepatol 2016;22:423-431.

32. Lin CL, Tseng TC, Kao JH. What can we learn from hepatitis B virus clinical cohorts? Liver Int 2015;35 Suppl 1:91-99.

33. Tseng TC, Liu CJ, Yang HC, et al. High levels of hepatitis B surface antigen increase risk of hepatocellular carcinoma in patients with low HBV load. Gastroenterology 2012;142:1140-1149.

34. Tseng TC, Liu CJ, Yang HC, et al. Serum hepatitis B surface antigen levels help predict disease progression in patients with low hepatitis B virus loads. Hepatology 2013;57:441-450.

35. Kim GA, Lim YS, Han S, et al. High risk of hepatocellular carcinoma and death in patients with immune-tolerant-phase chronic hepatitis B. Gut 2018;67:945-952.

36. Simonetti J, Bulkow L, McMahon BJ, et al. Clearance of hepatitis B surface antigen and risk of hepatocellular car- cinoma in a cohort chronically infected with hepatitis B virus. Hepatology 2010;51:1531-1537.

37. Zhu L, Zhai X, Wang Q, et al. Incidence and determinants of spontaneous hepatitis B surface antigen seroclearance and seroconversion in hepatitis B e antigen-negative chronic infection patients: a population-based prospective cohort. J Viral Hepat 2018;25:1588-1598.

38. Ahn SH, Park YN, Park JY, et al. Long-term clinical and histological outcomes in patients with spontaneous hepatitis B surface antigen seroclearance. J Hepatol 2005;42:188-194.

39. Park YM, Lee SG. Clinical features of HBsAg seroclearance in hepatitis B virus carriers in South Korea: a retrospective longitudinal study. World J Gastroenterol 2016;22:9836-9843.

40. Kim GA, Lee HC, Kim MJ, et al. Incidence of hepatocellular carcinoma after HBsAg seroclearance in chronic hepatitis B patients: a need for surveillance. J Hepatol 2015;62:1092-1099.

41. Kim JH, Lee YS, Lee HJ, et al. HBsAg seroclearance in chronic hepatitis B: implications for hepatocellular carcinoma. J Clin Gastroenterol 2011;45:64-68.

42. Yang BM, Kim DJ, Byun KS, Kim HS, Park JW, Shin S. The societal burden of HBV-related disease: South Korea. Dig Dis Sci 2010;55:784-793.

43. Ganem D, Prince AM. Hepatitis B virus infection: natural history and clinical consequences. N Engl J Med 2004;350:1118-1129.

44. Cho HY, Kim CH, Go UY, Lee HJ. Immunization decision-making in the Republic of Korea: the structure and functioning of the Korea Advisory Committee on Immunization Practices. Vaccine 2010;28 Suppl 1:A91-A95.

45. World Health Organization Regional Office for the Western Pacific. Meeting report: the third hepatitis B expert resource panel consultation; 2015 Jan 12-13; Seoul, Korea. Available from: http://iris.wpro.who.int/bitstream/handle/10665.1/11153/RS_2015_GE_64_KOR_eng.pdf.

46. Brown RS Jr, McMahon BJ, Lok AS, et al. Antiviral therapy in chronic hepatitis B viral infection during pregnancy: a systematic review and meta-analysis. Hepatology 2016;63:319-333.

47. Wen WH, Huang CW, Chie WC, et al. Quantitative maternal hepatitis B surface antigen predicts maternally transmitted hepatitis B virus infection. Hepatology 2016;64:1451-1461.

48. Pan CQ, Duan Z, Dai E, et al. Tenofovir to prevent hep- 
atitis B transmission in mothers with high viral load. $\mathrm{N}$ Engl J Med 2016;374:2324-2334.

49. Lin Y, Liu Y, Ding G, et al. Efficacy of tenofovir in preventing perinatal transmission of $\mathrm{HBV}$ infection in pregnant women with high viral loads. Sci Rep 2018;8:15514.
50. Hyun MH, Lee YS, Kim JH, et al. Systematic review with meta-analysis: the efficacy and safety of tenofovir to prevent mother-to-child transmission of hepatitis B virus. Aliment Pharmacol Ther 2017;45:1493-1505. 